\title{
Ultra-Wideband Systems with Energy Harvesting Units for Sensors, 5G, IoT and Medical Systems
}

\author{
Albert Sabban \\ Electrical Engineering Department, Ort Braude College, Karmiel, Israel \\ Email: sabban@netvision.net.il
}

How to cite this paper: Sabban, A. (2021) Ultra-Wideband Systems with Energy Harvesting Units for Sensors, 5G, IoT and Medical Systems. Journal of Sensor Technology, 11, 1-17.

https://doi.org/10.4236/jst.2021.111001

Received: December 15, 2020

Accepted: March 9, 2021

Published: March 12, 2021

Copyright $\odot 2021$ by author(s) and Scientific Research Publishing Inc. This work is licensed under the Creative Commons Attribution International License (CC BY 4.0).

http://creativecommons.org/licenses/by/4.0/

(c) (i) Open Access

\begin{abstract}
The high tech industrial revolution in the last fifty years depleted and ruined the planet natural resources. Energy harvesting is the main challenge in the research in green technologies. Compact wideband efficient antennas are crucial for energy harvesting portable sensors and systems. Small antennas have low efficiency. The efficiency of 5G, IoT communication and energy harvesting systems may be improved by using wideband efficient passive and active antennas. The system dynamic range may be improved by connecting amplifiers to the small antenna feed line. Ultra-wideband portable harvesting systems are presented in this paper. This paper presents new Ultra-Wideband energy harvesting system and antennas in frequencies ranging from $0.15 \mathrm{GHz}$ to $18 \mathrm{GHz}$. Three wideband antennas cover the frequency range from 0.15 $\mathrm{GHz}$ to $18 \mathrm{GHz}$. A wideband metamaterial antenna with metallic strips covers the frequency range from $0.15 \mathrm{GHz}$ to $0.42 \mathrm{GHz}$. The antenna bandwidth is around $75 \%$ for VSWR better than 2.3:1. A wideband slot antenna covers the frequency range from $0.4 \mathrm{GHz}$ to $6.4 \mathrm{GHz}$. A wideband fractal notch antenna covers the frequency range from $6 \mathrm{GHz}$ to $18 \mathrm{GHz}$. Printed passive and active notch and slot antennas are compact, low cost and have low volume. The active antennas may be employed in energy harvesting portable systems. The antennas and the harvesting system components may be assembled on the same, printed board. The printed notch and slot antennas bandwidth are from $75 \%$ to $100 \%$ for VSWR better than $3: 1$. The slot and notch antenna gain is around $3 \mathrm{dBi}$ with efficiency higher than $90 \%$. The antennas electrical parameters were computed in free space and near the human body. There is a good agreement between computed and measured results.
\end{abstract}

\section{Keywords}

Wearable Sensors, Medical Applications, Active Systems, Medical and Sport Sensors 


\section{Introduction}

In the last fifty years, the universe has suffered rapid changes in climate. It is obvious in 2020 to most of the world population that green energy is crucial to save the universe from climate changes. The rapid spread of diseases and macro-parasites, and the extinction of species are the direct result of climate changes. In the last twenty years, the idea of using free space energy in the forms of light, heat, vibration, electromagnetic waves, muscle motion and other types of energy, has become useful and challenging. A number of methods to produce electricity from these different types of energy sources have been investigated and developed [1] [2] [3] [4]. Energy harvesting systems provide green energy and may eliminate the need to replace batteries every day and the usage of power cords. Batteries and cables waste pollute the environment. To use as much free space energy as possible it is important to harvest the electromagnetic power from wideband range of wireless communication systems. In these cases, we should use ultra-wideband antennas. Moreover, a programmable array with two to four antennas can harvest energy from $100 \mathrm{MHz}$ to $18 \mathrm{GHz}$. The energy harvesting antenna must satisfy the requirements related to the system application. Due to considerably low-power electromagnetic energy densities in free space, highly efficient antennas are significant. The antennas should operate at a specific frequency range and polarization. The antenna radiation pattern should have a wide beam width or omnidirectional radiation pattern. Several printed antennas were employed for harvesting energy applications [4] [5] [6] [7]. Patch and slot antennas are widely used in communication and medical system [4]-[24]. Wideband printed compact slot and notch antennas are good choices to function in wideband harvesting energy systems. Slot and notch antennas are compact, low cost, flexible, and efficient. Moreover, a compact low-cost energy harvesting network and matching network may be achieved by integrating the system RF components with the antennas on the same substrate. Printed compact antennas are widely presented in the literature in the last twenty years as referred in [7]-[25]. Human body effect on the electrical performance of wearable medical system and antennas at microwave frequencies should be considered. Electrical properties of human tissues have been presented in several papers such as [26] [27]. Several wearable antennas were presented in books and papers in the last years as referred in [27]-[36]. Printed notch and slot antennas for harvesting energy applications are rarely presented in the literature. New ultra-wideband wearable antennas for 5G, IoT and medical RF systems with energy harvesting units are presented in this paper.

\section{Energy Harvesting Systems for 5G, IoT, Medical and Computer Industry}

In the last decade, there is a significant increase in the amount of electromagnetic energy in the air. Almost every person has a cellular phone tablet and other communication devices. In electromagnetic energy harvesting systems, the electromagnetic waves propagating in free space may be received by harvesting an- 
tennas and converted to electric energy that is used to charge batteries and for other devices. The expected amount of radio wave in the air in 2019 was 33 Exa-bytes, EB, per month. However, the expected amount of radio wave in the air in 2025 is expected to be 164 Exa-bytes per month, see Table 1. Table 1 presents the expected amount of radio wave in the air for $2 \mathrm{G}, 3 \mathrm{G}, 4 \mathrm{G}$, and $5 \mathrm{G}$ networks. 5G is forecast to account for $45 \%$ of global mobile data traffic by 2025 . Computations per KWh from 1985 to 2018 are listed in Table 2. Energy sources used in harvesting systems are listed in Table 3. Communication services such as television, GSM, wireless local area networks, WLAN, and Wi-Fi covers the frequency range from $0.2 \mathrm{GHz}$ to $5.4 \mathrm{GHz}$. Wireless communication systems operate in the frequencies from $700 \mathrm{MHz}$ to $2700 \mathrm{MHz}$. Medical systems operate in the frequencies from $200 \mathrm{MHz}$ to $1200 \mathrm{MHz}$. WLAN systems operate in the frequencies from $5400 \mathrm{MHz}$ to $5900 \mathrm{MHz}$.

RF energy is inversely proportional to distance and therefore drops as the distance from a source is increased. Harvested power from RF energy sources is lower than $0.1 \mathrm{~mW} / \mathrm{cm}^{2}$. Electromagnetic energy harvesting system is shown in Figure 1. A programmable array with 3 to 4 antennas can harvest RF energy from $0.15 \mathrm{GHz}$ up to $18 \mathrm{GHz}$. The received RF energy may be combined after transformed to DC power.

Table 1. Expected amount of radio wave in free space from 2015 up to 2025.

\begin{tabular}{cccc}
\hline Year & $\begin{array}{c}\text { Total amount of radio } \\
\text { wave in free space } \\
\text { EB per month }\end{array}$ & $\begin{array}{c}\text { Amount of radio wave in free } \\
\text { space EB per month } \\
2 \mathrm{G}, 3 \mathrm{G}, 4 \mathrm{G}\end{array}$ & $\begin{array}{c}\text { Amount of radio wave in } \\
\text { free space EB per month }\end{array}$ \\
\hline 2015 & 4.4 & 4.4 & $5 \mathrm{G}$ \\
2017 & 11 & 11 & 0 \\
2019 & 33 & 33 & 0 \\
2021 & 60 & 50 & 10 \\
2023 & 100 & 75 & 25 \\
2025 & 164 & 85 & 79 \\
\hline
\end{tabular}

Table 2. Computations per KWh from 1985 to 2018.

\begin{tabular}{lc}
\hline Year & Computations per KWh $(1 \mathrm{E}+09)$ \\
1985 & 50 \\
1987 & 100 \\
1992 & 1000 \\
1997 & 10,000 \\
2003 & 100,000 \\
2008 & $1,000,000$ \\
2010 & $15,000,000$ \\
2012 & $20,000,000$ \\
2014 & $30,000,000$ \\
2016 & $40,000,000$ \\
2018 & $50,000,000$ \\
\hline
\end{tabular}


Table 3. Energy sources used in harvesting systems.

\begin{tabular}{cccc}
\hline Energy Source & Type & Efficiency & Estimated Harvested Power \\
\hline Light & Outdoor/Indoor & $10 \%-25 \%$ & $100 \mathrm{~mW} / \mathrm{cm}^{2}$ \\
Thermal & Human & $\sim 0.1 \%$ & $60 \mu \mathrm{W} / \mathrm{cm}^{2}$ \\
& Industrial & $\sim 3 \%$ & $\sim 1-10 \mathrm{~mW} / \mathrm{cm}^{2}$ \\
Vibration & $\sim$ Hz-human & $20 \%-50 \%$ & $\sim 4 \mu \mathrm{W} / \mathrm{cm}^{3}$ \\
& $\sim \mathrm{kHz}$-machines & & $\sim 800 \mu \mathrm{W} / \mathrm{cm}^{3}$ \\
Electromagnetic & $900-2700 \mathrm{MHz}$ & $\sim 50 \%$ & $0.1 \mu \mathrm{W} / \mathrm{cm}^{2}$ \\
& Wi-Fi, WLAN & & $0.001 \mu \mathrm{W} / \mathrm{cm}^{2}$ \\
RF GSM 1 GHz & Wireless GSM & $\sim 50 \%$ & 0.1 up to $1 \mathrm{~mW} / \mathrm{cm}^{2}$ \\
\hline
\end{tabular}

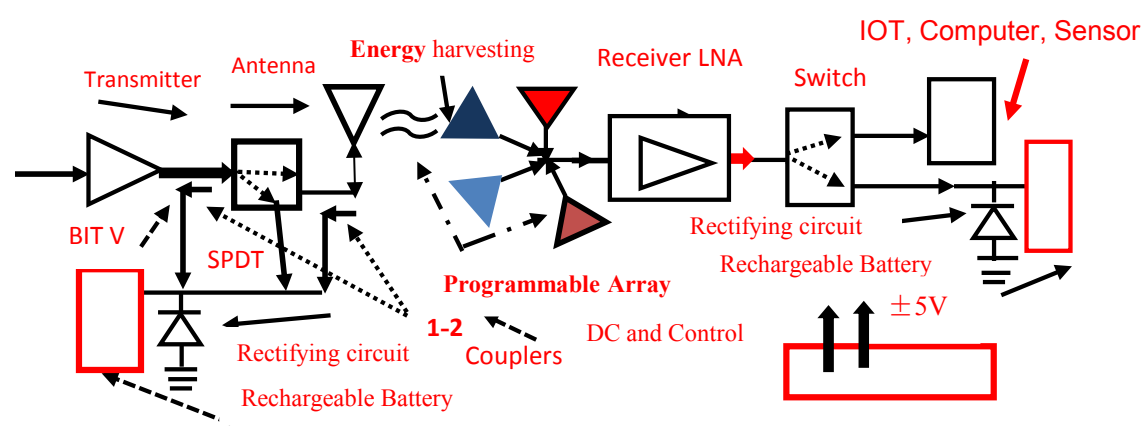

Figure 1. Dual mode programmable array energy harvesting system.

The RF energy harvesting system consists of antennas, matching and feed networks, rectifying circuit, and a rechargeable battery. The harvesting energy system operates as a dual mode RF harvesting system. The harvesting unit can be part of a medical, IoT, computer, and smartphone. The LNA DC bias voltages are supplied by the receiving system The Low Noise Amplifier is part of the. The energy coupled to the transmitting built in test, $-20 \mathrm{~dB}$, may be harvested and used to charge a battery. We can calculate the energy harvesting link budget by using Equation (1) if the antennas are matched and there are no losses in the medium. However, if the antennas are not matched and the RF energy propagates in a lossy media, we can calculate the energy harvesting link budget by using Equation (2). Wireless smartphone using standard 802.11 can transmit up to 1 Watt. Free Space Loss $\left(L_{p}\right)$ represents propagation loss in free space. Losses due to attenuation in atmosphere, $L_{a}=\mathrm{e}^{-\alpha r}$, should be accounted for in the transmission equation.

$$
\begin{gathered}
P_{r}=P_{t} G_{t} G_{r}\left(\frac{\lambda}{4 \pi R}\right)^{2} \\
P_{r}=P_{t} G_{r} G_{t}\left(\frac{\lambda}{4 \pi r}\right)^{2}\left(1-\left|\Gamma_{t}\right|^{2}\right)\left(1-\left|\Gamma_{r}\right|^{2}\right)\left|a_{t} a_{r}^{*}\right|^{2} \mathrm{e}^{-\alpha r}
\end{gathered}
$$

The attenuation constant is $\alpha$. Where, $L_{p}=\left(\frac{4 \pi R}{\lambda}\right)^{2}$. The received power may be given as: $P_{r}=\frac{P_{t} G_{t} G_{r}}{L_{p}}$. Losses due to polarization mismatch, 
$L_{p o l}=\left|a_{t} a_{r}^{*}\right|^{2}$, should also be accounted. Losses associates with receiving antenna, $L_{r a}$, and with the receiver, $L_{r}=1-\left|\Gamma_{r}\right|^{2}$, should be accounted in computation of transmission budget. Losses associates with the transmitting antenna as written as, $L_{t a}=1-\left|\Gamma_{t}\right|^{2}$. Where: $\Gamma_{r}$ is the reflection coeficient of the receiving antenna.

$$
P_{r}=\frac{P_{t} G_{t} G_{r}}{L_{p} L_{a} L_{t a} L_{r a} L_{p o l} L_{o} L_{r}}
$$

$\Gamma_{t}$ is the reflection coeficient of the transmitting antenna. $P_{t}=P_{\text {out }} / L_{t}$.

$P_{t}=$ Transmitting antenna power. $L_{t}=$ Loss between power source and antenna.

$E I R P=$ Effective isotropic radiated power. Where, $E I R P=P_{t} G_{t}$. Where,

$$
\begin{aligned}
P_{r} & =\frac{P_{t} G_{t} G_{r}}{L_{p} L_{a} L_{t a} L_{r a} L_{p o l} L_{\text {other }} L_{r}} \\
& =\frac{E I R P \times G_{r}}{L_{p} L_{a} L_{t a} L_{r a} L_{p o l} L_{\text {other }} L_{r}} \\
& =\frac{P_{\text {out }} G_{t} G_{r}}{L_{t} L_{p} L_{a} L_{t a} L_{r a} L_{p o l} L_{\text {other }} L_{r}}
\end{aligned}
$$

$G$, Gain in $\mathrm{dB}$; and $L$, Loss in $\mathrm{dB}$ are written as: $G=10 \cdot \log \left(\frac{P_{\text {out }}}{P_{\text {in }}}\right) \mathrm{dB}$, $L=10 \log \left(\frac{P_{\text {in }}}{P_{\text {out }}}\right) \mathrm{dB}$.

The received power $P_{r}$ in $\mathrm{dBm}$ may be calculated by using Equation (5). The received power $P_{r}$ is referred to as the "Carrier Power". Personal Computer Memory Cards using standard 802.11 can transmit up to $100 \mathrm{~mW}$.

$$
P_{r}=E I R P-L_{t a}-L_{p}-L_{a}-L_{p o l}-L_{r a}-L_{o t h e r}+G_{r}-L_{r}
$$

Figure 2 presents a wideband receiving system, $500 \mathrm{MHz}-18 \mathrm{GHz}$, with energy harvesting units.

Figure 3 presents a wideband transmitting system, $500 \mathrm{MHz}$ to $18 \mathrm{GHz}$, with energy harvesting units.

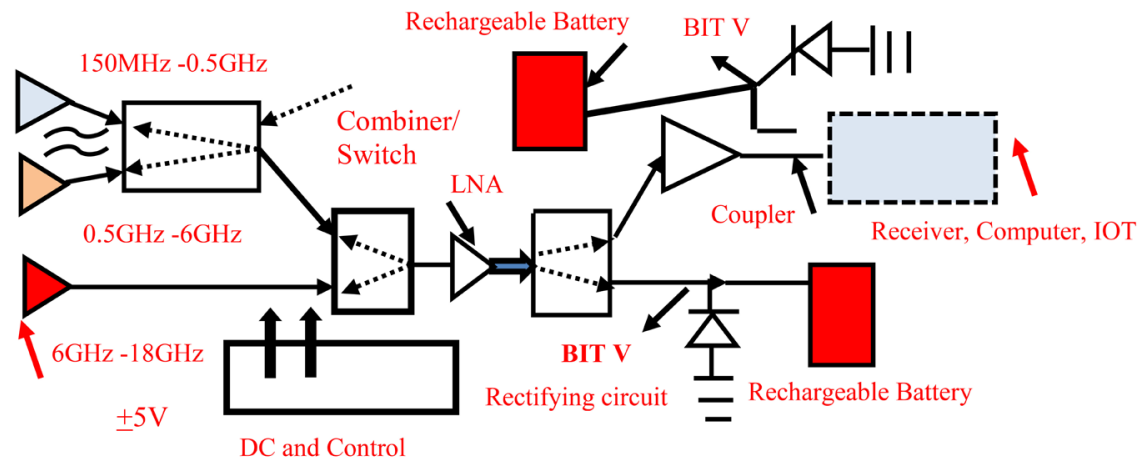

Figure 2. Wideband harvesting receiving programmable array system. 


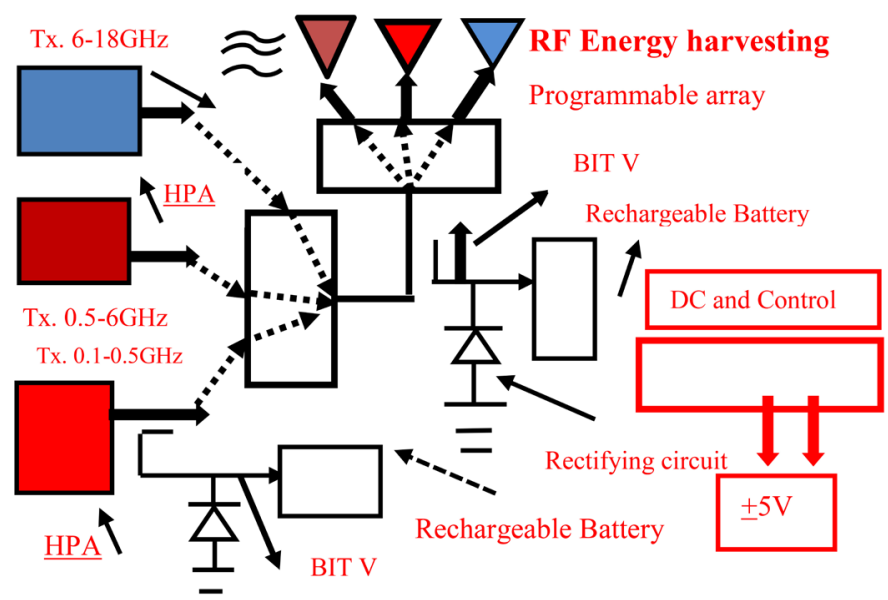

Figure 3. Optimized harvesting transmitting programmable array system.

Three wideband antennas are employed in the receiving and transmitting systems presented in Figure 2 and Figure 3. The first antenna covers frequencies from $150 \mathrm{MHz}$ to $0.5 \mathrm{GHz}$. The second antenna covers frequencies from 500 $\mathrm{MHz}$ to $6 \mathrm{GHz}$. The third antenna covers frequencies from $6 \mathrm{GHz}$ to $18 \mathrm{GHz}$. The receiving and transmitting systems can harvest energy from $150 \mathrm{MHz}$ to 18 GHz. Almost in every transmitting or receiving channel part of the energy, -10 $\mathrm{dB}$ to $-20 \mathrm{~dB}$, is coupled to a built in test port. This RF energy can be transformed to DC energy and can be used to charge electrical devices. In the receiving channel the received $\mathrm{RF}$ energy from $150 \mathrm{MHz}$ to $6 \mathrm{GHz}$ is transferred via a wideband combiner or SPDT to a second SPDT that is connected to the $6 \mathrm{GHz}$ to $18 \mathrm{GHz}$ antenna. The output of the second SPDT is connected to a third wideband SPDT via a wideband LNA. The LNA is part of the receiving channel. The output of the third SPDT transfer the receiving RF energy to the receiving channel or to the harvesting system. A wideband amplifier transfers the received $R F$ signal to the receiver. The received RF energy is coupled, $-10 \mathrm{~dB}$ to $-20 \mathrm{~dB}$, is coupled to a Built in Test port. This RF energy is transformed into DC energy and may be used to charge electrical devices. A wideband switching matrix connects three power amplifiers to three transmitting antennas. The first antenna covers the frequency range from $150 \mathrm{MHz}$ to $0.5 \mathrm{GHz}$. The second antenna covers frequencies from $500 \mathrm{MHz}$ to $6 \mathrm{GHz}$. The third antenna covers frequencies from $6 \mathrm{GHz}$ to $18 \mathrm{GHz}$. A DC unit supplies the bias voltages to the amplifiers and controls the switching matrix state. The harvesting system may consist one to three antennas according to the system requirements. The antennas may cover the frequency range from $150 \mathrm{MHz}$ to $6.4 \mathrm{GHz}$ only.

\section{Wideband $150 \mathrm{MHz}$ to $0.4 \mathrm{GHz}$, Energy Harvesting Antenna}

RF energy in the frequency range from $150 \mathrm{MHz}$ to $500 \mathrm{MHz}$ may be harvested by a wideband compact metamaterial antenna as presented in Figure 4. The antenna is a dual polarized printed dipole and slot antennas with Split Ring Reso- 
nators and metallic strips. The microstrip loaded dipole antenna with SRR provides horizontal polarization. The slot antenna provides vertical polarization. The dipole feed network is printed on the first layer. The radiating dipole with SRR is printed on the second layer. The thickness of each layer is $0.8 \mathrm{~mm}$. The length of the antenna with SRR is $19.8 \mathrm{~cm}$. The SRR ring width is $1.4 \mathrm{~mm}$ the spacing between the rings is $1.4 \mathrm{~mm}$. The antennas have been analyzed by using electromagnetic software. The matching stubs and metallic strips locations and dimensions have been optimized to get the best VSWR results. The S11 parameter of the metamaterial antenna with metallic strips is presented in Figure 5. The antenna bandwidth is around 75\% for VSWR better than 2.3:1.

The antenna radiation pattern is shown in Figure 6 . The $3 \mathrm{D}$ computed radiation pattern is shown in Figure 7. Directivity and gain of the antenna with SRR are around $5 \mathrm{dBi}$.

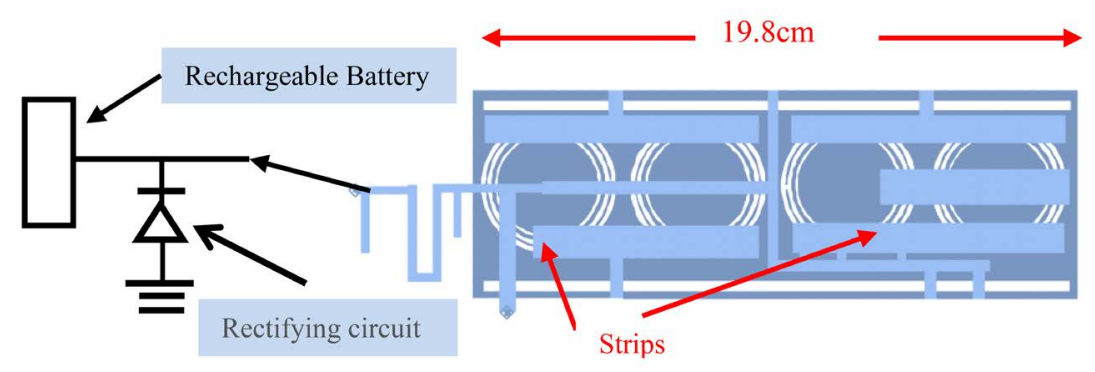

Figure 4. Wideband antenna with SRR and Metallic strips.

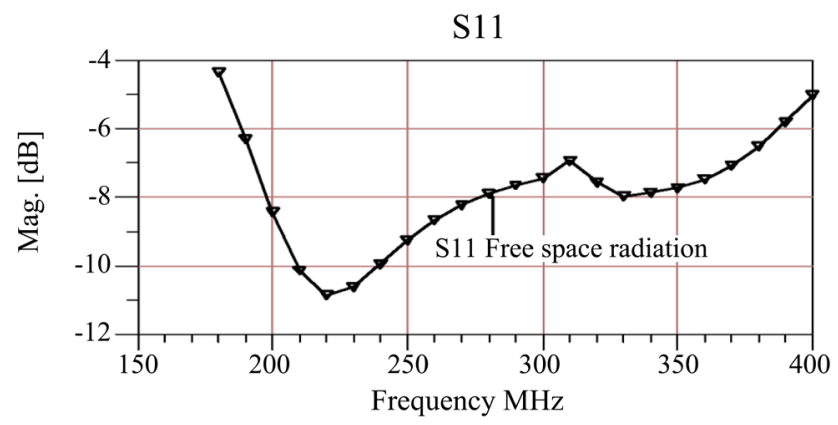

Figure 5. S11 for antenna with SRR and metallic strips.

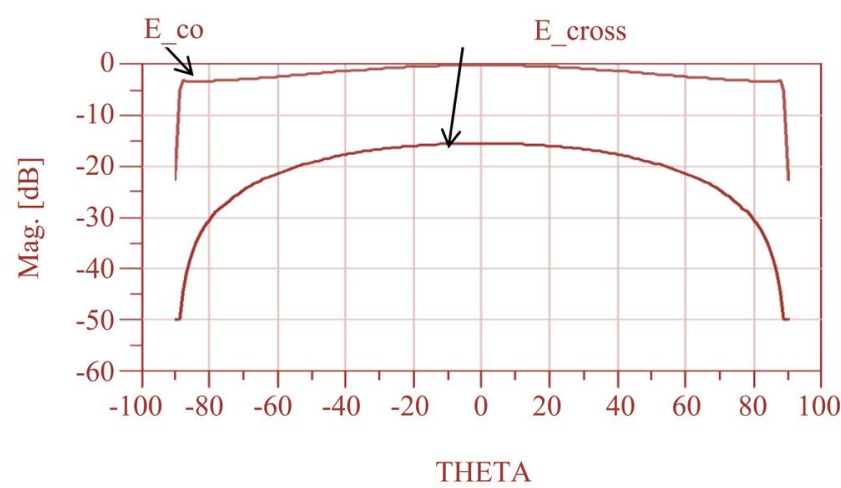

Figure 6. Radiation pattern for antenna with SRR and metallic strips. 

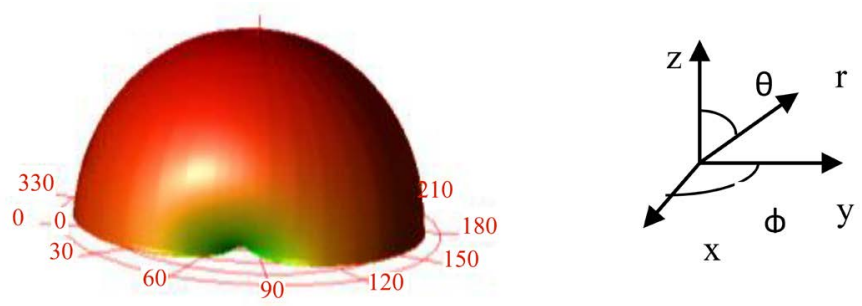

Figure 7. 3D Radiation pattern for antenna with SRR.

\section{Wideband $400 \mathrm{MHz}$ to $6.4 \mathrm{GHz}$, Energy Harvesting Slot Antenna}

RF energy in the frequency range from $400 \mathrm{MHz}$ to $6.4 \mathrm{GHz}$ may be harvested by a wideband compact $\mathrm{T}$ shape slot antenna as presented in Figure 8 . The slot antenna is printed on a dielectric substrate with dielectric constant of 2.2 and 1.2 mm thick. The dimensions of the slot antenna shown in Figure 8 are $116 \times 70 \times$ $1.2 \mathrm{~mm}$. The antenna electrical parameters were calculated and optimized by using ADS software [37]. The S11 parameter of the wideband T shape slot antenna is presented in Figure 9. The radiation pattern of the wideband $\mathrm{T}$ shape slot antenna at $1.5 \mathrm{GHz}$ is shown in Figure 10. The antenna gain is $3 \mathrm{~dB}$.

\section{New Compact Ultra-Wideband Harvesting Notch Antenna 5.8 $\mathrm{GHz}$ to $18 \mathrm{GHz}$}

A wideband notch antenna with fractal structure has been designed. The antenna is printed on a dielectric substrate with dielectric constant of 2.2 and $1.2 \mathrm{~mm}$ thick. The notch antenna is shown in Figure 11. The notch antenna dimensions are $11 \times 7.7 \mathrm{~mm}$. The antenna center frequency is $12 \mathrm{GHz}$. The antenna bandwidth is around $100 \%$ for $\mathrm{S} 11$ lower than $-5 \mathrm{~dB}$, as presented in Figure 12. The notch antenna VSWR is better than 3:1 for more than $90 \%$ of the frequency range from $5.8 \mathrm{GHz}$ to $18 \mathrm{GHz}$. The antenna beam width is around $84^{\circ}$. The antenna gain is around $3.5 \mathrm{dBi}$. Figure 13 presents the radiation pattern of the wideband notch antenna with fractal structure at $8 \mathrm{GHz}$. The antenna matching network was optimized to get better $\mathrm{S} 11$ results at $16 \mathrm{GHz}$ to $18 \mathrm{GHz}$. The length and width of the stubs were tuned to get better $\mathrm{S} 11$ results at $16 \mathrm{GHz}$ to $18 \mathrm{GHz}$.

\section{Wideband Energy Harvesting Systems and Applications}

As presented in Figure 1 the programmable array energy harvesting system consists of wideband programmable antenna network, a rectifying circuit, and a rechargeable battery. A rectifier is a circuit that converts electromagnetic energy, alternating current AC, to direct current (DC). Half wave rectifier or full wave rectifier are used to convert electromagnetic energy to DC electrical energy. A Half wave rectifier with a capacitor is presented in Figure 14. A half-wave rectifier conducts only during the positive voltage half cycle. It allows only one half of the electromagnetic waveform to pass through the load. The rectifier output DC voltage, $V_{O D C}$ is given in Equation (5). The rectifier output voltage may be 
improved by connecting a capacitor in shunt to the resistor. The time constant $\tau$ should be lower than $T$.

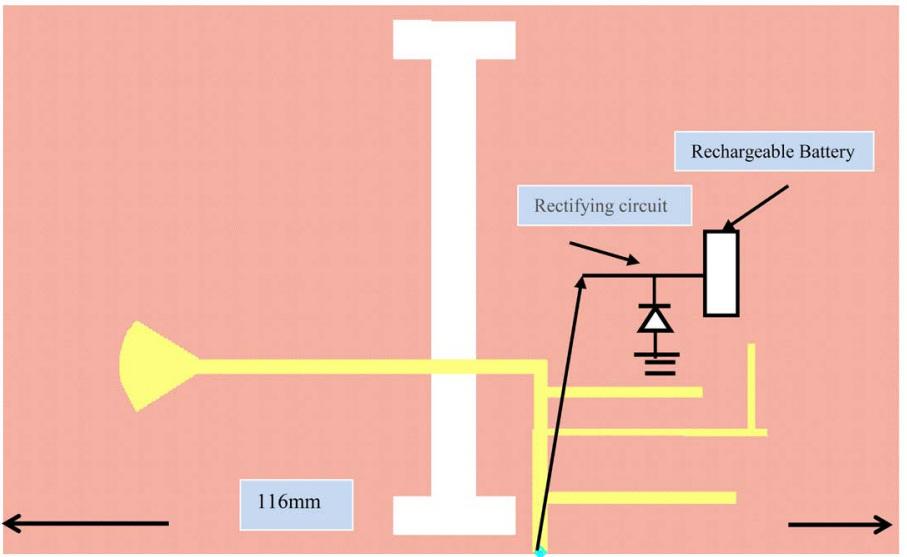

Figure 8. A ultra-wideband T shape printed harvesting slot antenna.

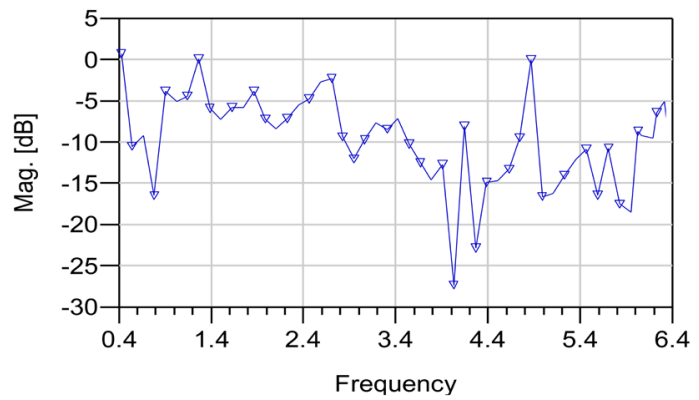

Figure 9. S11 of a wideband printed T Shape energy harvesting slot antenna.

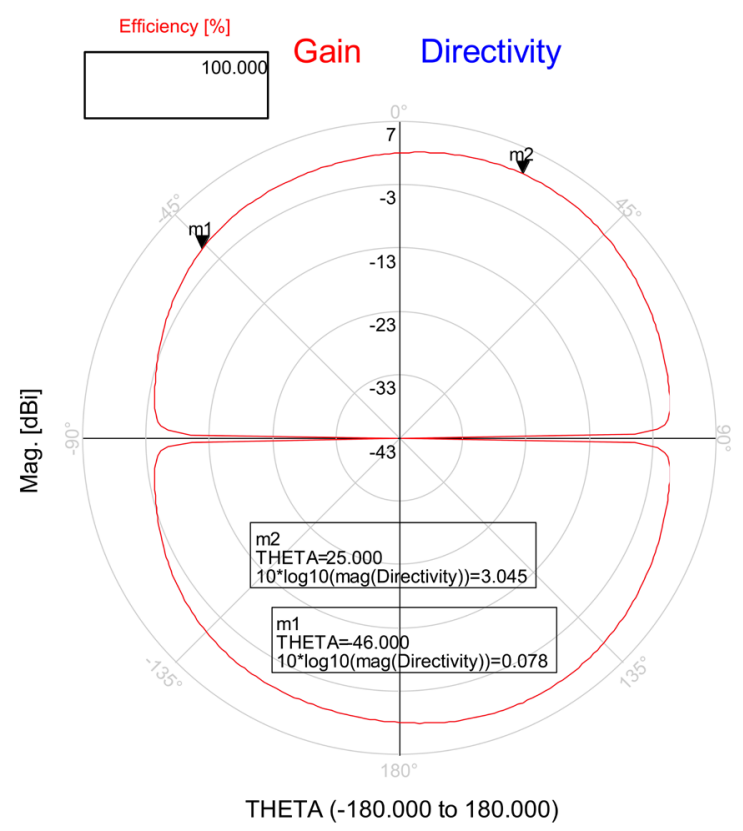

Figure 10. Radiation pattern of a wideband wearable printed $\mathrm{T}$ shape slot antenna at $1.5 \mathrm{GHz}$. 


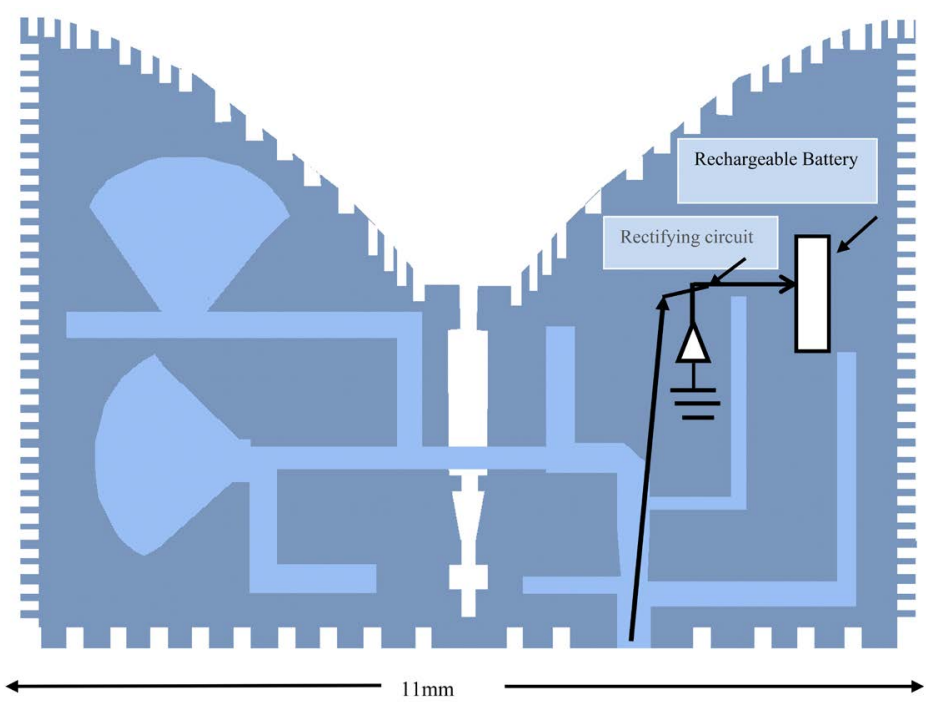

Figure 11 . A wideband $5.8 \mathrm{GHz}$ to $18 \mathrm{GHz}$ notch antenna with fractal structure.

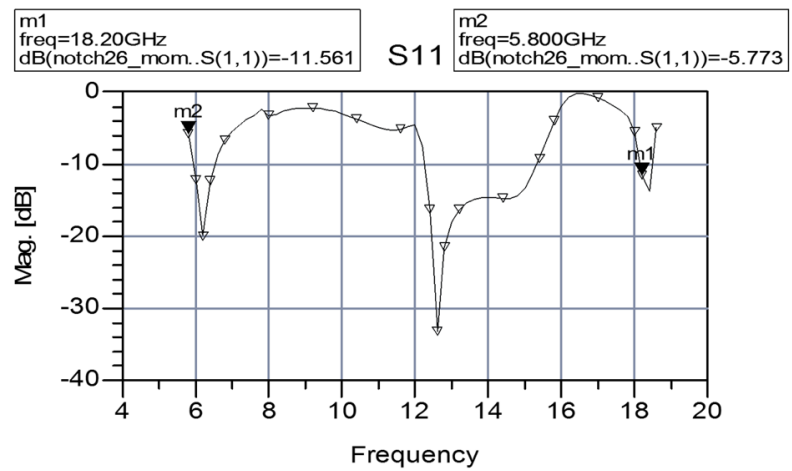

Figure 12. A wideband $5.8 \mathrm{GHz}$ to $18 \mathrm{GHz}$ notch antenna with fractal structure, $\mathrm{S} 11$ results.

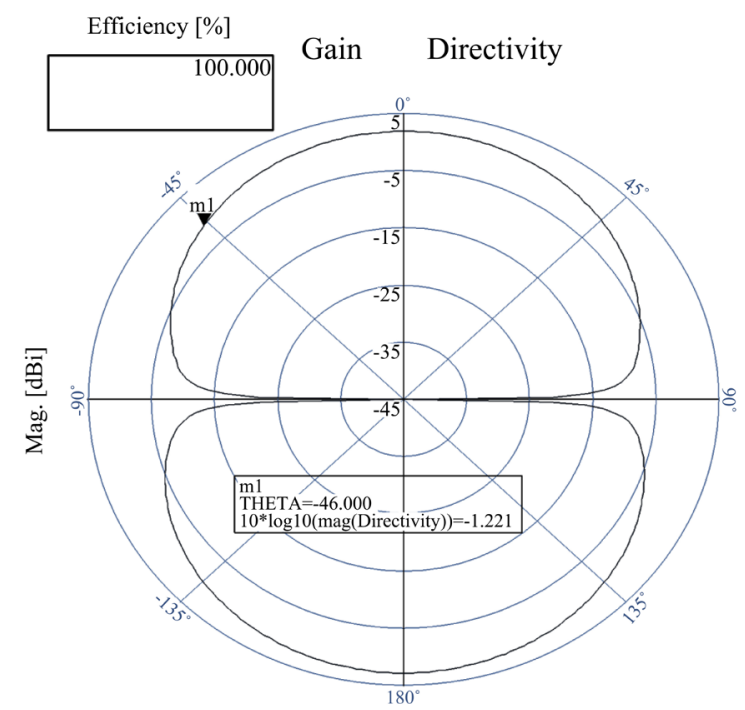

THETA (-180.000 to 180.000$)$

Figure 13. Radiation pattern of the wideband notch antenna with fractal structure at $8 \mathrm{GHz}$. 

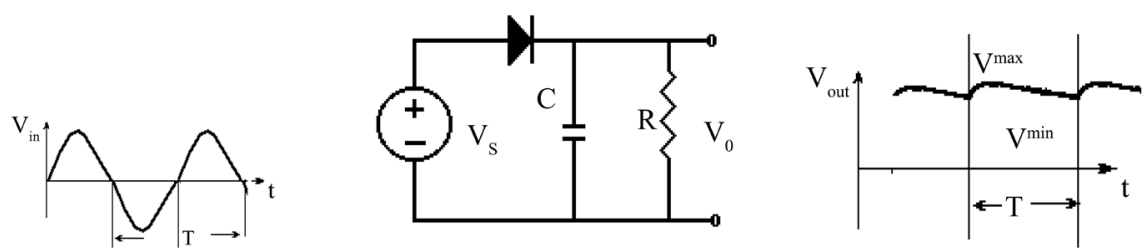

Figure 14. Half wave voltage rectifier with a capacitor.

$$
\begin{gathered}
V_{O, D C}=\frac{1}{2 \pi} \int_{0}^{2 \pi} V_{O}^{M A X} \sin (\omega t) \mathrm{d}(\omega t) ; \omega=2 \pi f \\
V_{O}=V_{S}-V_{D O N} \approx V_{S} ; \quad V_{O}^{M A X}=V_{m} \\
V_{O D C}=V_{m} / \pi \\
V_{\text {ripple }}=V_{r}=V_{\text {max }}-V_{\text {min }}=\frac{V_{D C}}{f C R}
\end{gathered}
$$

where, $\tau=R C \ll T$. The half wave rectifier efficiency is $40.6 \%$. Only $40.6 \%$ of the input AC power is converted into DC power. Where $r f$ is the diode resistance is negligible as compared to $R$.

A Half wave bridge rectifier is shown in Figure 15. The bridge full wave rectifier circuit is used to convert AC energy to DC energy and for DC power suppliers. The bridge rectifier consists of four diodes D1 through D4, as shown in Figure 15. During the positive input half cycle, terminal A will be positive and terminal B will be negative. Diodes D1 and D2 will become forward biased and D3 and D4 will be reversed biased. The rectifier output DC voltage, $V_{O D C}=2 V_{m} / \pi$, The rectifier output voltage may be improved by connecting a capacitor in shunt to the resistor as shown in Figure 15.

The half wave rectifier efficiency is $81.2 \%$ as presented in Equation (7). This means that only $81.2 \%$ of the input AC power is converted into DC power. The harvested voltage from the three antennas is $V_{\text {Total }}$ as written in Equation (8). The total DC energy is $P_{\text {Total }}$ as written in Equation (9). The actual harvested energy is $P$ as written in Equation (10).

$$
\begin{gathered}
\eta=\frac{\text { DC output power }}{\text { AC input power }}=\frac{\left(\frac{2 I_{m}}{\pi}\right)^{2} R}{\left(\frac{I_{m}}{2}\right)^{2}(R+r f)} \sim 0.812 \\
V_{\text {Total }}=V_{1}+V_{2}+V_{3} \\
P_{\text {Total }}=\frac{V_{\text {Total }}^{2}}{R}=I_{m}^{2} R \\
P=0.81 P_{\text {Total }}=0.81 \frac{V_{\text {Total }}^{2}}{R}=0.81 I_{m}^{2} R
\end{gathered}
$$

A Schottky diode may be used in the rectifier circuit. Schottky diodes are semiconductor diodes which have a low forward voltage drop and a very fast switching action. There is a small voltage drop across the diode terminals when 
current flows through the diode. The voltage drop of a Schottky diode is usually between 0.15 and 0.4 volts. This lower voltage drop provides better system efficiency and higher switching speed. A normal diode has a voltage drop between 0.6 to 1.7 volts. RF energy harvesting systems can be used to charge wearable devices. Figure 16 presents a wearable harvesting system with a wearable battery charger attached to a patient shirt. A wideband energy Harvesting panel with three antennas is presented in Figure 17.

The panel dimensions are $20 \times 12 \times 0.02 \mathrm{~cm}$. This panel can harvest energy in frequencies from $150 \mathrm{MHz}$ to $18 \mathrm{GHz}$ as part of communication, medical, and IoT systems.
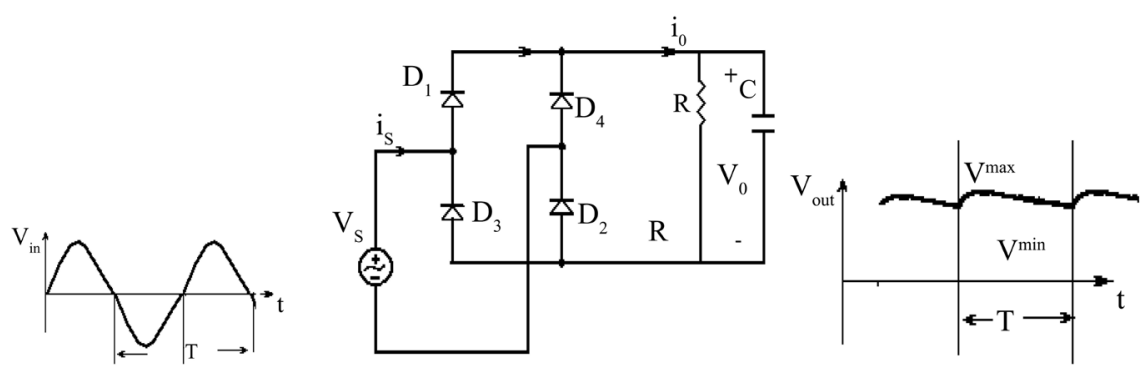

Figure 15. Full wave bridge voltage rectifier with a capacitor.

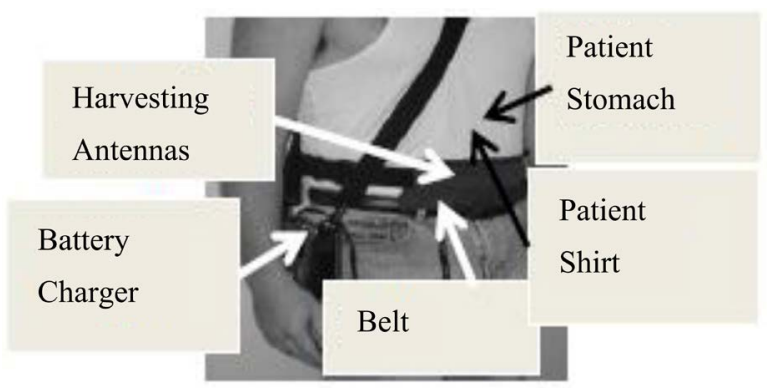

Figure 16. Medical wearable harvesting system.

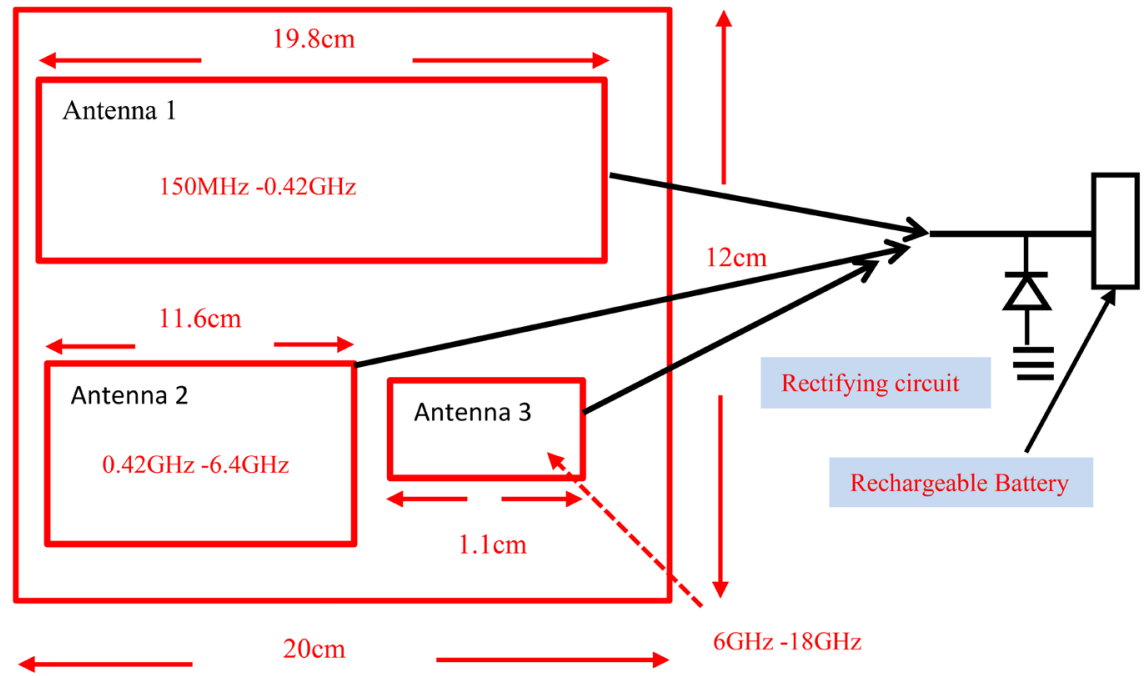

Figure 17. Wideband RF energy harvesting panel. 
Figure 18 presents a photo of a wideband metamaterial antenna with metallic strips, $150 \mathrm{MHz}-0.5 \mathrm{GHz}$. Figure 18(a) presents the antenna feed network and the metallic strips. Figure 18(b) presents the dual polarized metamaterial antenna with four SRRs. Figure 19 presents a photo of a wideband T shape slot antenna, $420 \mathrm{MHz}-6.4 \mathrm{GHz}$. These antennas can be used to harvest RF energy to charge wearable devices and sensors. The UHF dual polarized antenna can be attached to the patient stomach or back. The wideband $\mathrm{T}$ shape slot can be attached to the patient stomach or back. The wideband compact notch antenna can be also attached to the patient stomach or back. These antennas provide a wideband wearable communication system with a wideband RF harvesting system. Wearable Body Area Network with energy harvesting system for medical applications is presented in Figure 20.

A comparison of computed and measured results of compact wearable antennas for medical, 5G and IoT systems is listed in Table 4. Printed dipoles with and without SRR were presented in [9] [10].

Table 4. Comparison of electrical characteristics of energy harvesting antennas [9] [10].

\begin{tabular}{cccccc}
\hline Antenna & Frequency (GHz) & Bandwidth \% & VSWR & $\begin{array}{c}\text { Computed } \\
\text { Gain dBi }\end{array}$ & $\begin{array}{c}\text { Measured } \\
\text { Gain dBi }\end{array}$ \\
\hline Printed dipole [9] & 0.43 & $5-10$ & $2: 1$ & $2-3$ & $2-3$ \\
Dipole with SRR & 0.4 & $8-12$ & $2: 1$ & $5-7$ & $5-7$ \\
Dipole (SRR and strips) [10] & 0.14 to 0.42 & UWB & $2.5: 1$ & $5-7.5$ & $5-7.5$ \\
Slot [10] & 1 to 4 & UWB & $2: 1$ & 3 & 3 \\
T shape slot [10] & 0.4 to 6.4 & UWB & $3: 1$ & 3 & 3 \\
Notch [10] & 6 to 18 & UWB & $3: 1$ & 3 & $2-3$ \\
\hline
\end{tabular}

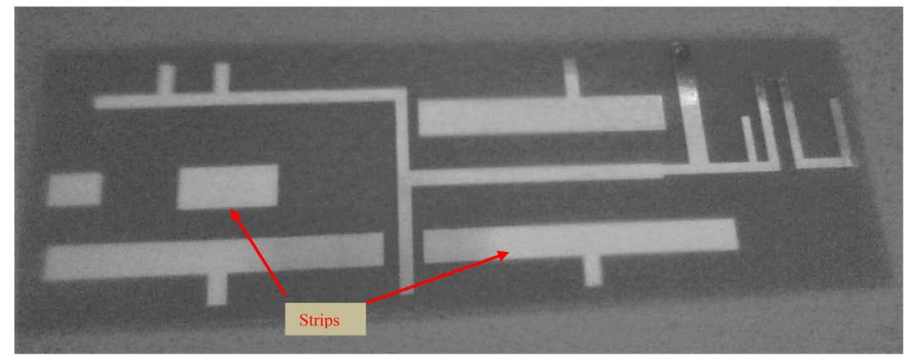

(a)

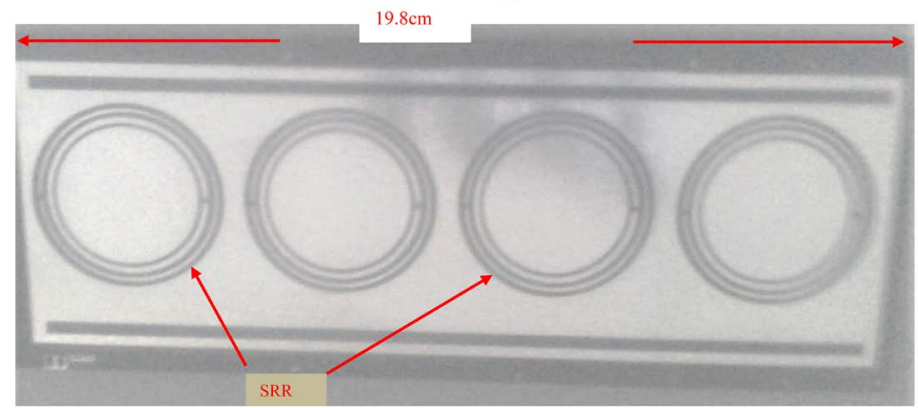

(b)

Figure 18. Wideband Energy harvesting metamaterial UHF antenna. (a) The antenna feed network and metallic strips. (b) Dual polarized UHF energy harvesting metamaterial antenna with four SRRs. 


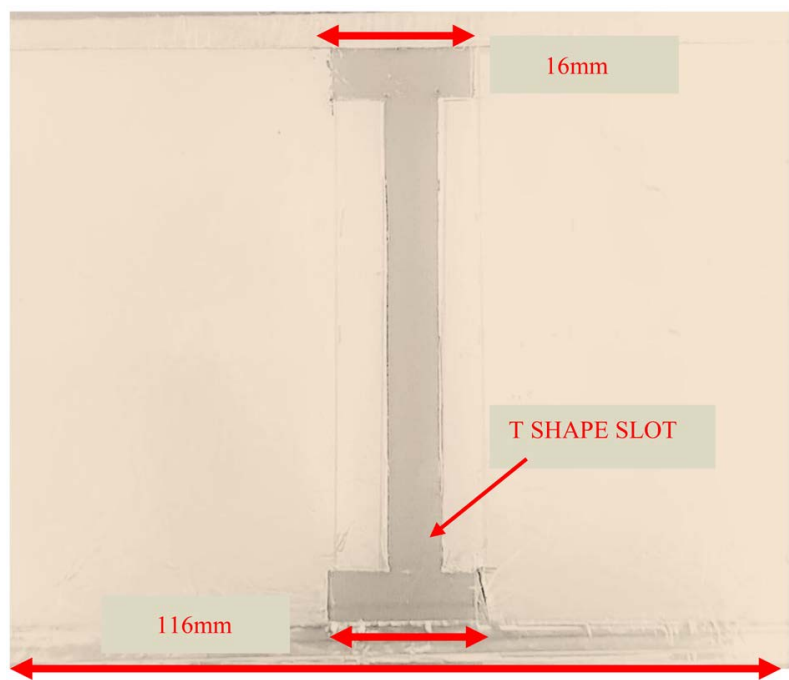

Figure 19. A photo of wideband energy harvesting slot antenna, $400 \mathrm{MHz}-6 \mathrm{GHz}$.

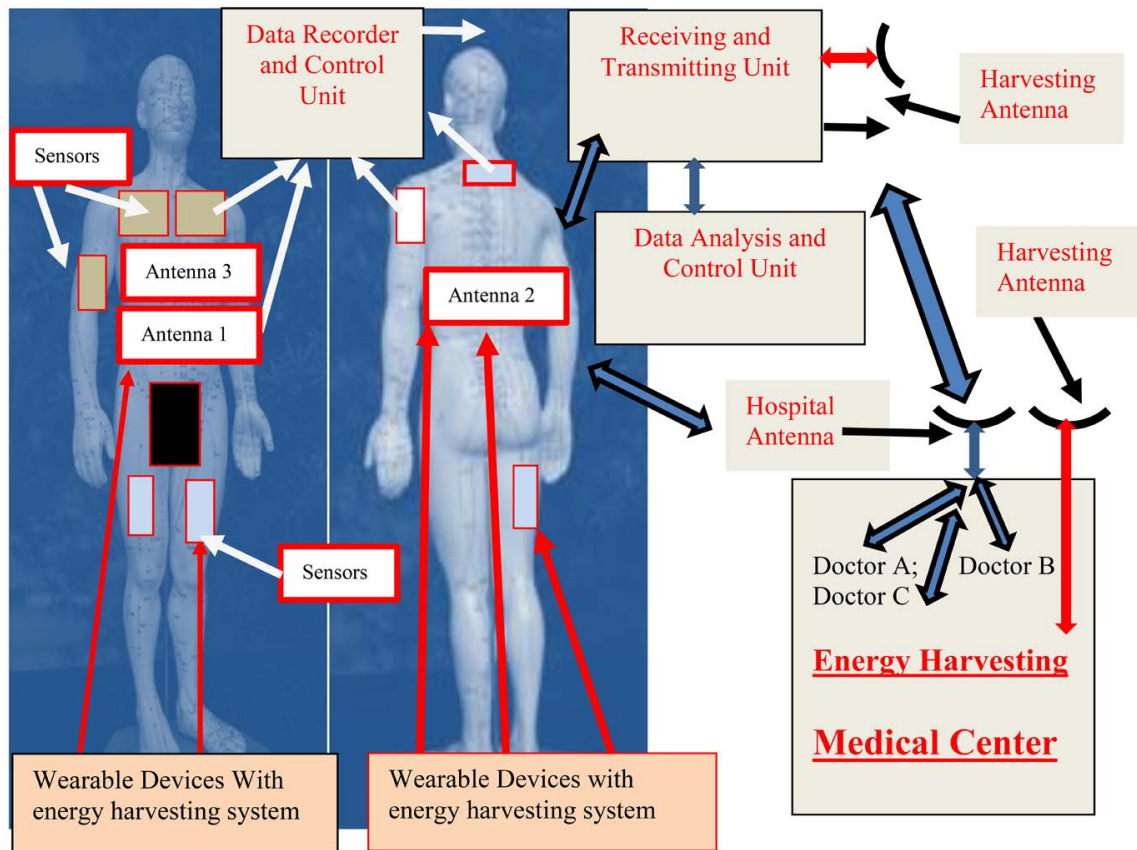

Figure 20. Wearable Body Area Network with energy harvesting system for medical applications.

\section{Conclusion}

This paper presents a new Ultra-Wideband energy harvesting system and antennas in frequencies ranging from $0.15 \mathrm{GHz}$ to $18 \mathrm{GHz}$. Three wideband antennas cover the frequency range from $0.15 \mathrm{GHz}$ to $18 \mathrm{GHz}$. A wideband metamaterial antenna with metallic strips covers the frequency range from $0.15 \mathrm{GHz}$ to $0.42 \mathrm{GHz}$. A wideband slot antenna covers the frequency range from $0.4 \mathrm{GHz}$ to $6.4 \mathrm{GHz}$. A wideband fractal notch antenna covers the frequency range from 6 $\mathrm{GHz}$ to $18 \mathrm{GHz}$. The electromagnetic energy is converted to DC energy that may 
be employed to charge batteries, wearable medical devices, IoT, laptop batteries and commercial Body Area Networks, BANs. The harvesting energy system operates as a dual mode RF harvesting system. The harvesting unit can be part of a medical, IoT, computer, and smartphone. The notch and slot antennas were analyzed by using 3D full-wave software. Harvested power from RF transmitting links is usually lower than $0.1 \mu \mathrm{W} / \mathrm{cm}^{2}$. All antennas presented in this paper can operate also as active antennas. Active antennas may improve the energy harvesting system efficiency. The wideband RF energy harvesting system consists of wideband antenna, DC and control unit, a rectifying circuit, and a rechargeable battery. The harvesting energy system operates as a Dual Mode Energy harvesting system. The active devices DC bias voltages are supplied by the communication system. The wideband programmable energy harvesting panel can harvest energy in frequencies from $150 \mathrm{MHz}$ to $18 \mathrm{GHz}$ as part of communication, medical, and IoT systems. The antennas presented in this paper provide a wideband wearable communication system with a wideband RF harvesting system. There is a good agreement between computed and measured results.

\section{Conflicts of Interest}

The author declares no conflicts of interest regarding the publication of this paper.

\section{References}

[1] Paradiso, J.A. and Starner, T. (2005) Energy Scavenging for Mobile and Wireless Electronics. IEEE Pervasive Computing, 4, 18-27. https://doi.org/10.1109/MPRV.2005.9

[2] Valenta, C.R. and Durgin, G.D. (2014) Harvesting Wireless Power: Survey of Energy-Harvester Conversion Efficiency in Far-Field, Wireless Power Transfer Systems. IEEE Microwave Magazine, 15, 108-120. https://doi.org/10.1109/MMM.2014.2309499

[3] Nintanavongsa, P., Muncuk, U., Lewis, D.R. and Chowdhury, K.R. (2012) Design Optimization and implementation for RF Energy Harvesting Circuits. IEEE Journal on Emerging and Selected Topics in Circuits and Systems, 2, 24-33. https://doi.org/10.1109/JETCAS.2012.2187106

[4] Devi, K.K.A., Sadasivam, S., Din, N.M. and Chakrabarthy, C.K. (2011) Design of a $377 \Omega$ Patch Antenna for Ambient RF Energy Harvesting at Downlink Frequency of GSM 900. Proceedings of the 17 th Asia Pacific Conference on Communications, Sabah, 2-5 October 2011, 492-495. https://doi.org/10.1109/APCC.2011.6152859

[5] Rahim, R.A., Malek, F., Anwar, S.F.W., Hassan, S.L.S., Junita, M.N. and Hassan, H.F. (2013) A Harmonic Suppression Circularly Polarized Patch Antenna for an RF Ambient Energy Harvesting System. Proceedings of the IEEE Conference on Clean Energy and Technology, Lankgkawi, 18-20 November 2013, 33-37. https://doi.org/10.1109/CEAT.2013.6775595

[6] Krakauskas, M., Sabaawi, A.M.A. and Tsimenidis, C.C. (2014) Suspended Patch Microstrip Antenna with Cut Rectangular Slots for RF Energy Harvesting. Proceedings of the 10th Loughborough Antennas and Propagation Conference, Loughborough, 10-11 November 2014, 304-307. 
https://doi.org/10.1109/LAPC.2014.6996382

[7] Sabban, A. (2015) Low Visibility Antennas for Communication Systems. CRC Press, Boca Raton. https://doi.org/10.1201/b18919

[8] Sabban, A. (2018) Wearable Communication Systems and Antennas for Commercial, Sport, and Medical Applications. IOP Publishing Ltd, Bristol. https://doi.org/10.1088/2053-2563/aade55

[9] Sabban, A. (2016) Wideband RF Technologies and Antenna in Microwave Frequencies. John Wiley \& Sons, Inc., Hoboken.

https://doi.org/10.1002/9781119048640

[10] Sabban, A. (2017) Novel Wearable Antennas for Communication and Medical Systems. CRC Press, Boca Raton. https://doi.org/10.1201/b22261

[11] Sabban, A. and Gupta, K.C. (1991) Characterization of Radiation Loss from Microstrip Discontinuities Using a Multiport Network Modeling Approach. IEEE Transactions on Microwave Theory and Techniques, 39, 705-712. https://doi.org/10.1109/22.76436

[12] Sabban, A. (1983) A New Wideband Stacked Microstrip Antenna. IEEE Antenna and Propagation Symposium, Houston, June 1983, 63-66.

[13] Sabban, A. and Navon, E. (1983) A MM-Waves Microstrip Antenna Array. IEEE Symposium, Tel-Aviv, March 1983.

[14] Balanis, C.A. (1996) Antenna Theory: Analysis and Design. 2nd Edition, Wiley, Hoboken.

[15] Sabban, A. (1991) Multiport Network Model for Evaluating Radiation Loss and Coupling among Discontinuities in Microstrip Circuits. PhD Thesis, University of Colorado at Boulder, Boulder.

[16] Sabban, A. (1986) Microstrip Antenna Arrays. U.S. Patent No. 4623893.

[17] Sabban, A. (1981) Wideband Microstrip Antenna Arrays. IEEE Antenna and Propagation Symposium MELCOM, Tel-Aviv, June 1981.

[18] Fujimoto, K. and James, J.R. (1994) Mobile Antenna Systems Handbook. Artech House, Boston.

[19] Sabban, A. (2016) New Wideband Notch Antennas for Communication Systems. Wireless Engineering and Technology Journal, 7, 75-82.

http://dx.doi.org/10.4236/wet.2016.72008

[20] Sabban, A. (2012) Dual polarized dipole wearable antenna. U.S Patent No. 8203497.

[21] Sabban, A. (2012) Wideband Tunable Printed Antennas for Medical Applications. Proceedings of the 2012 IEEE International Symposium on Antennas and Propagation, Chicago, 8-14 July 2012, 1-2. https://doi.org/10.1109/APS.2012.6349023

[22] Sabban, A. (2013) New Wideband Printed Antennas for Medical Applications. IEEE Transactions on Antennas and Propagation, 61, 84-91.

https://doi.org/10.1109/TAP.2012.2214993

[23] Sabban, A. (2013) Comprehensive Study of Printed Antennas on Human Body for Medical Applications. International Journal of Advance in Medical Science, 1, 1-10.

[24] Kastner, R., Heyman, E. and Sabban, A. (1988) Spectral Domain Iterative Analysis of Single and Double-Layered Microstrip Antennas Using the Conjugate Gradient Algorithm. IEEE Transactions on Antennas and Propagation, 36, 1204-1212. https://doi.org/10.1109/8.8596

[25] Sabban, A. (2011) Microstrip Antenna Arrays. In: Nasimuddin, N., Ed., Microstrip Antennas, InTech, London, 361-384. https://doi.org/10.5772/14394 
http://www.intechopen.com/articles/show/title/microstrip-antenna-arrays

[26] Chirwa, L.C., Hammond, P.A., Roy, S. and Cumming, D.R.S. (2003) Electromagnetic Radiation from Ingested Sources in the Human Intestine between $150 \mathrm{MHz}$ and 1.2 GHz. IEEE Transaction on Biomedical eng, 50, 484-492.

https://doi.org/10.1109/TBME.2003.809474

[27] Werber, D., Schwentner, A. and Biebl, E.M. (2006) Investigation of RF Transmission Properties of Human Tissues. Advances in Radio Science, 4, 357-360. https://doi.org/10.5194/ars-4-357-2006

[28] Gupta, B., Sankaralingam, S., Dhar, S. (2010) Development of Wearable and Implantable Antennas in the Last Decade: A Review. 2010 10th Mediterranean Microwave Symposium, Guzelyurt, 25-27 August 2010, 251-267.

https://doi.org/10.1109/MMW.2010.5605178

[29] Thalmann, T., Popovic, Z., Notaros, B.M. and Mosig, J.R. (2009) Investigation and Design of a Multi-Band Wearable Antenna. 3rd European Conference on Antennas and Propagation, Berlin, 23-27 March 2009, 462-465.

[30] Salonen, P., Rahmat-Samii, Y. and Kivikoski, M. (2004) Wearable Antennas in the Vicinity of Human Body. IEEE Antennas and Propagation Society Symposium, 2004, Monterey, 20-25 June 2004, 467-470. https://doi.org/10.1109/APS.2004.1329675

[31] Kellomaki, T., Heikkinen, J., Kivikoski, M. (2006) Wearable Antennas for FM Reception. 1 st European Conference on Antennas and Propagation, Nice, 6-10 November 2006, 1-6. https://doi.org/10.1109/EUCAP.2006.4585031

[32] Sabban, A. (2011) New Compact Wideband Printed Antennas for Medical Applications. 2011 IEEE International Symposium on Antennas and Propagation (APSURSI), Spokane, 3-8 July 2011, 251-254. https://doi.org/10.1109/APS.2011.5996689

[33] Sabban, A. (2009) Wideband Printed Antennas for Medical Applications. 2009 Asia Pacific Microwave Conference, Singapore, 7-10 December 2009, 393-396. https://doi.org/10.1109/APMC.2009.5384521

[34] Alomainy, A., Sani, A., Rahman, A., Santas, J.G. and Hao, Y. (2009) Transient Characteristics of Wearable Antennas and Radio Propagation Channels for Ultrawideband Body-Centric Wireless Communication. IEEE Trans. on Antennas and Propagation, 57, 875-884. https://doi.org/10.1109/TAP.2009.2014588

[35] Klemm, M. and Troester, G. (2006) Textile UWB Antenna for Wireless Body Area Networks. IEEE Transactions on Antennas and Propagation, 54, 3192-3197. https://doi.org/10.1109/TAP.2006.883978

[36] Izdebski, P.M., Rajagoplan, H. and Rahmat-Sami, Y. (2009) Conformal Ingestible Capsule Antenna: A Novel Chandelier Meandered Design. IEEE Transactions on Antennas and Propagation, 57, 900-909. https://doi.org/10.1109/TAP.2009.2014598

[37] ADS Software (n.d.) Agilent.

http://www.home.agilent.com/agilent/product.jspx?cc=IL\&lc=eng\&ckey=1297113\& $\underline{\text { nid }=34346.0 .00 \& \mathrm{rd}=1297113}$ 